\title{
INFLUENCING THE FUTURE: ADOLESCENT GIRLS' PERCEPTIONS OF CYBERSECURITY CAREERS
}

\author{
Pam Rowland, Dakota State University, pam.rowland@dsu.edu \\ Cherie Noteboom, Dakota State University, cherie.noteboom@dsu.edu
}

\begin{abstract}
Adolescents are influenced in multiple ways and through multiple channels. Influencers strongly affect adolescent's decision-making related to activities, classes, and career choices. Middle school is a key time when girls tend to explore or turn away from cyber fields. Through qualitative survey research with open coding data analysis, this research answers the question "What are the adolescent girls' influencers as related to exploration of the cybersecurity field?" by presenting the SCCIF Model. The factors of influence discovered are school, community/groups, career perception, individual, and family which transition through positive, negative, or neutral stages, and can move fluidly between them.
\end{abstract}

Keywords: cybersecurity, influencers, gender, technology, education, adolescence

\section{INTRODUCTION}

Data breaches are a big problem with over 446 million records exposed in 2018 (Ellis, 2019; Statista, 2019). A corresponding problem is the shortage of cybersecurity professionals globally. According to the world's largest nonprofit association of certified cybersecurity pros, ISC ${ }^{2}$, the shortage is close to three million globally ((ISC)2, 2018 ) with only $20 \%$ of the work force being women, which indicates women are an untapped resource to help fill the need while providing valuable insight and knowledge to the field. The national effort to recruit more women in cybersecurity is making an impact (up from $11 \%$ to $20 \%$ in the last three years), but there is still a significant gender gap (Morgan, 2018). Women can help fill the need for cybersecurity workers, and research shows that middle school is a pivotal time for students' decision making and exploring of new opportunities. It is a time when society and adolescent girls' (ages 12-14) contacts are a large influence. During these years, students tend to have a decline in motivation and performance as they transition from elementary school to middle school (Midgley, Feldlaufer, \& Eccles, 1989). Motivation and performance can depend on the characteristics of the learning environment and can even be maintained or improved with attention given to the environment (Anderman \& Midgley, 1997). The environment of middle school students includes factors of influence, which will be explored in this research.

As girls enter middle school their social group fluctuates and girls tend to reassess their academic abilities (Pajares \& Schunk, 2001) through their widely expanded social reference group, coupled with the shift in evaluation standards. Consequently, perceptions of academic competence typically begin to decline during middle school (Harter, 1996; Midgley et al., 1989). This shift in perceptions may create the feeling of 'belonging uncertainty' for girls as they seek areas of study where they feel they belong. Research has shown that these societal level factors have influenced female students' career choices and commitment to a particular field (Shih, Pittinsky, \& Ambady, 1999; Steele \& Ambady, 2006).

Although several studies have investigated adolescent girls' perceptions of STEM fields (Dasgupta \& Stout, 2014; Grossman \& Porche, 2014; Rozek, Hyde, Svoboda, Hulleman, \& Harackiewicz, 2015), no one has specifically addressed adolescent girls' influencers toward the cybersecurity field. Rowland studied anchors for adolescent girls in the cybersecurity career path which lead to the CISSE (Community, Influence, Social Media Connection, SelfEfficacy, Education) framework (Rowland, 2018) The CISSE framework shows that community, influence, social 
media connection, increase in self-efficacy, and education are promising practices to anchor girls in a cybersecurity career path. These promising practices inform programs that are recruiting and motivating girls to explore this field.

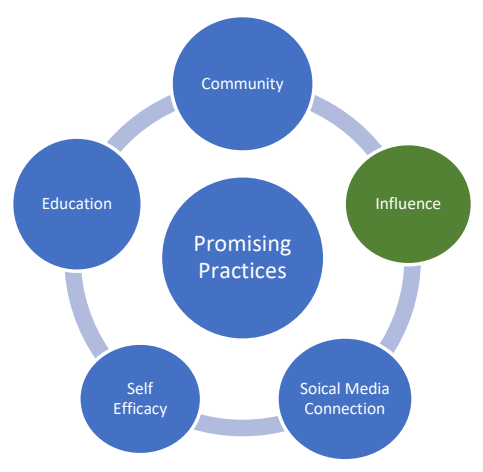

Figure 1. CISSE Model (Rowland, 2018)

Rowland and Noteboom conducted initial investigations and discovered that more sub-categories needed to be explored to provide recommendations to influencers to assist middle school girls to consider cybersecurity allowing for improving motivational factors and performance (Rowland \& Noteboom, 2019). This research expands previous efforts and evaluates the "Influence" segment of the CISSE model and investigates the question, "What are the adolescent girls' influencers as related to exploration of the cybersecurity field?" By exploring the influencers role, we provide a stronger argument related to the impact influencers have on adolescent girls' career choices.

\section{BACKGROUND LITERATURE}

\section{Promoting STEM at Middle School Age}

STEM is defined as Science, Technology, Engineering and Math (Bybee, 2010). Technology is defined as, "the branch of knowledge that deals with the creation and use of technical means and their interrelation with life, society, and the environment, drawing upon such subjects as industrial arts, engineering, applied science, and pure science" (Technology, 2019). Within STEM, many equate technology to computer related fields (Brown, Brown, Reardon, \& Merrill, 2011). Computers are one form of technology, but technology includes much more than just computers. It is for this reason that cybersecurity is included in the 'technology' portion of STEM. The International Technology and Engineering Educators Association indicate that technology and engineering education is problem-based learning by students utilizing math, science, engineering and technology principles. These studies involve "designing, developing, and utilizing technological systems; open-ended, problem-based design activities; cognitive, manipulative, and effective learning strategies; applying technological knowledge and processes to real world experiences using up-to date resources; and working individually as well as in a team to solve problems" (Iteea, 2019). Dutta, et al states that "Cybersecurity is an integral part of STEM, and we must secure our cyberspace for the future by integrating cybersecurity" (Dutta \& Mathur, 2012).

Evidence suggests that girls become uninterested in computer science and cybersecurity during adolescence, and that waiting to engage female students until high-school tends to be too late (Jethwani, Memon, Seo, \& Richer, 2017; LeClair \& Pheils, 2016). Adolescent girls are more likely to withdraw from subjects they do not feel confident in or do not feel like they belong (Margolis \& Fisher, 2003). A 2017 survey by Microsoft found that young girls in Europe become interested in STEM subjects around the age of 11. Girls lost interest around the age of 15. "Conformity to social expectations, gender stereotypes, gender roles and lack of role models continue to channel girls' career choices away from STEM fields," said psychology professor Martin Bauer of the London School of Economics, who helped 
coordinate the survey of 11,500 girls across 12 European countries (Petroff, 2017). Once interest is lost, it doesn't appear that girls' interest ever rebounds.

The underrepresentation of girls and women in cybersecurity and computer science has a unique set of challenges. Girls tend to express less confidence and rate their computer knowledge lower than boys, however achievement levels are similar (Cooper, 2006; Moorman \& Johnson, 2003; Shapiro \& Williams, 2012). Girls also perceive the computer science field as masculine, 'geeky', and isolated (Cheryan, Drury, \& Vichayapai, 2013; Margolis \& Fisher, 2003; Shumba et al., 2013).

When individuals are in a state of belonging uncertainty, they may notice threatening cues that may otherwise be overlooked (Kleck \& Strenta, 1980; Mendoza-Denton, Downey, Purdie, Davis, \& Pietrzak, 2002). Young girls interested in computing notice the cues of conformity to social expectations, gender stereotypes, and gender roles. Middle school is a time when girls expand their social group and reassess their academic abilities (Pajares \& Schunk, 2001). Influential factors often pull girls into particular social or academic groups. The unique challenges girls face may cause them to lose the motivation to explore and perform well in the cyber sciences.

\section{Role Models and Influencers}

Career role models for adolescents are essential. Having career role models provides positive association to a career field (Flouri \& Buchanan, 2002). Female role models positively impact women in typically male-dominated fields (Grabisch \& Rusinowska, 2010; Young, Rudman, Buettner, \& McLean, 2013). Role models increase a woman's implicit identification within the field, while decreasing the implicit gendered stereotypes. Limited access to female role models in the information system profession reinforces the image of the field (Catherine Ashcraft, 2012), which is still male dominated. Girls need to have inspiring female teachers to provide role models of influence for girls. Girls who have inspiring teacher are 73\% more likely to go into computing (Cracking the Gender Code in Computing - Accenture and Girls Who Code, 2016). We also recognize that role models of either gender are important to adolescent girls.

Adolescents state that parents are the most influential people in their lives when it comes to career choices, however they lack confidence in their parent's ability to guide them in a cyber-related career (Securing Our Future: Closing the Cybersecurity Talent Gap, 2016). Many parents are unaware of the career opportunities in cybersecurity and are not equipped to guide their child's interest. A recent report by Bayer found that 31 percent of parents don't feel confident enough in their STEM knowledge to help their children engage ("Op-Ed: To Close Gap in STEM Pipeline, Engage Families," 2018).

Rowland's research showed that adolescents "relate cybersecurity workers to those within their range of influence; whether that be a parent, a teacher, or a tv personality. The image they relate to is changing from past studies where the image was a nerdy, white, male. The image given by the participants included computer focused, smart, professional looking - basically anyone" (Rowland, 2018, pg 32).

\section{RESEARCH METHODOLOGY AND DATA}

The research design utilizes qualitative research techniques and open-ended interviews for data collection. The interviews allowed for understanding of the phenomena within real-life contexts (Berg, 2004). This study addresses the real-life context of middle school girls' experiences and influences as related to cybersecurity. This grounded theory research uses theoretical sampling (Charmaz, 2006; Corbin \& Strauss, 1990; Glaser \& Strauss, 2009) seeking data from sources that will provide rich information regarding the emerging categories and theory rather than sources strictly intended to be statistically representative of the target population (Draucker, Martsolf, Ross, \& Rusk, 2007).

The qualitative techniques allowed exploration and focus on a smaller number of interviews to help illuminate, clarify, and deepen the understanding of middle school girls perceptions towards cybersecurity and the influences that affect decision making (Neuman, 2002). The study was approved by the Institutional Review Board (IRB). Participants for this study were middle school girls from Midwest schools. To develop the list of participants, middle school 


\section{Issues in Information Systems \\ Volume 20, Issue 1, pp. 168-177, 2019}

principals, teachers, and parents in the community were contacted. After interviewing a participant, they were asked for additional contacts who might be able to contribute to our study. This technique of identifying participants is sometimes called the snowball technique or chain referral technique and can be useful for qualitative research (Biernacki \& Waldorf, 1981). Information on the participants and generated transcripts are presented in Table 1, Demographics of Participants and Transcripts.

Table 1. Demographics of Participants and Transcripts

\begin{tabular}{|l|l|l|l|l|}
\hline Participant & Grade & $\begin{array}{l}\text { Location Midwest } \\
\text { (MW) or Southwest } \\
\text { (SW) }\end{array}$ & $\begin{array}{l}\text { Number of } \\
\text { transcribed } \\
\text { pages }\end{array}$ & Minutes of recording \\
\hline P1 & 8 & MW & 9 & 22 \\
\hline P2 & 8 & MW & 9 & 16 \\
\hline P3 & 8 & MW & 5 & 10 \\
\hline P4 & 8 & MW & 3 & 15 \\
\hline P5 & 8 & MW & 5 & 12 \\
\hline P6 & 6 & MW & 6 & 13 \\
\hline P7 & 7 & MW & 5 & 11 \\
\hline P8 & 6 & MW & 6 & 13 \\
\hline P9 & 6 & MW & 4 & 6 \\
\hline P10 & 8 & MW & 6 & 12 \\
\hline P11 & 6 & MW & 1 & 0 (recording failed) \\
\hline P13 & 6 & MW & 5 & 9 \\
\hline P14 & 7 & SW & 7 & 15 \\
\hline P15 & 8 & MW & 26 & 11 \\
\hline Totals & & & $\mathbf{9 7}$ & $\mathbf{1 6 5}$ \\
\hline & & & & \\
\hline
\end{tabular}

The process of the interview and data collection consisted of the following steps:

1. The parent was contacted to sign an informed consent form. I went over the form with the parent to point out the main points, which including indicating that the phone conversation would be recorded.

2. The parent and student signed the consent form.

3. The phone number given was called to set up an interview time.

4. At the interview time, a recording app was used to record the interviews.

5. The interviewee was informed that they did not have to answer any questions they did not want to and given the opportunity to ask any questions about the process.

6. Semi-structured interview questions are available in (Rowland, 2018).

7. After the interview was conducted, the recording was sent to a transcription company to be transcribed.

Fourteen in-depth interviews were conducted generating 165 recorded minutes and 97 pages of transcribed results. Additional detail on the development of the survey instrument are in (Rowland, 2018).

\section{ANALYSIS AND RESULTS}

The transcripts were analyzed with open coding techniques (Corbin \& Strauss, 2014; Glaser \& Strauss, 2009). Each researcher initially coded the transcripts independently. The second step was to compare the coding and develop concepts to group and conceptualize the codes. The final step was to form categories. The open coding of text allowed the researchers to discover influencer themes and quantify how often themes are addressed in a text. Table 2 shows the concepts by positive, negative and neutral and the count of each occurrence in the data.

Analysis revealed that middle school girls are influenced in several different areas, and an influencer result can be positive, neutral and negative. The influences appear to transition and cycle through positive, negative and neutral 


\section{Issues in Information Systems \\ Volume 20, Issue 1, pp. 168-177, 2019}

stages. The expectations and experiences of the girls appear to change as they are involved in their experiences. Most influences are positive, revealing that students appear to match their expectations with their experiences. The neutral and negative influences appear to indicate girls have engaged in an activity or experience that did not live up to their expectations. The spiraling of perceptions through positive, neutral and negative phases is a key discovery, reinforcing the responsibility of influencers to monitor the perceptions and engagement of girls in activities and be able to encourage them to maintain curiosity to continue to discover their interest areas. The influencer may have option to provide additional opportunities in an existing area or redirect them to discover the area of their passion.

Table 2. Breakdown of influencers

\begin{tabular}{|l|c|c|c|c|}
\hline & Positive & Neutral & Negative & Total \\
\hline School & 69 & 17 & 16 & $\mathbf{1 0 2}$ \\
\hline Career Perceptions & 41 & 25 & 13 & $\mathbf{7 9}$ \\
\hline Community Groups & 89 & 12 & 41 & $\mathbf{1 4 2}$ \\
\hline Individual & 27 & 14 & 8 & $\mathbf{4 9}$ \\
\hline Family & 116 & 13 & 3 & $\mathbf{1 3 2}$ \\
\hline Total & $\mathbf{3 4 2}$ & $\mathbf{8 1}$ & $\mathbf{8 1}$ & \\
\hline
\end{tabular}

From the discovered influencers, we created the SCCIF (School, Career, Community, Individual, Family) model which indicates that the major influencers are school, career perceptions, community groups, individual, and family. These findings reinforce the literature review and extend the findings in these areas. Table 2 shows a breakdown of each influence category and the count of positive, neutral and negative influential factors.

The SCCIF Model expands the "Influence" area of the CISSE Model and is displayed in Figure 2: SCCIF: Influencers of Adolescents. Our analysis elaborates on each influencer and reveals the data insights. Each of the influencer areas have positive, neutral, and negative responses that can influence a female adolescent's behavior. The following section discusses each influencer and supporting data analysis.
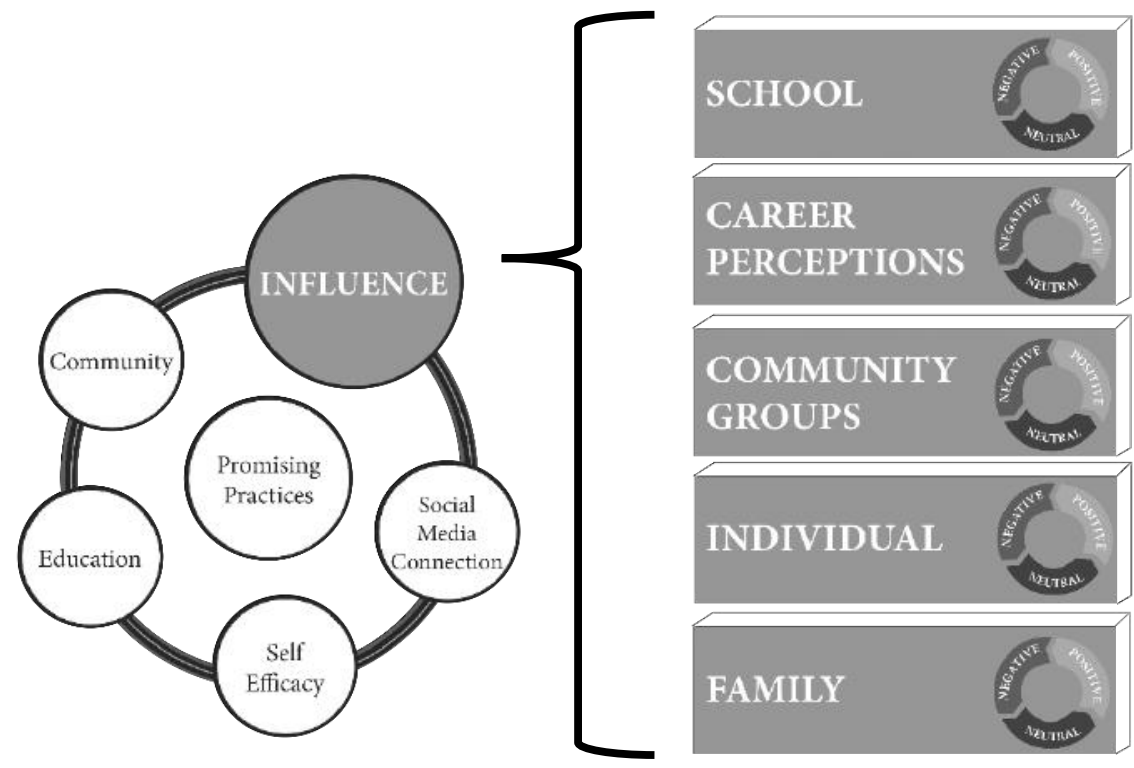

Figure 2. CISSEE Model influence area exploded to SCCIF Model: Influencers of Adolescents 


\section{Issues in Information Systems}

Volume 20, Issue 1, pp. 168-177, 2019

\section{School}

Teachers, coaches and curriculum were combined into this school category. Teachers influence students through teaching style and personality. Coaches influence students to work hard and try new things. Public school curriculum influences adolescents through selection of subjects either through pre-selected classes or self-selected. In middle school, most often the courses are pre-selected for the student.

P7 (when asked about a role model): "One of my teachers at school-she's my science teacher, she's also my cross country coach and she's really nice and she's just one of my role models. And she is just so nice and happy all the time and she inspires me to be happy all the time."

P2: "Well, my math teacher was really kind, and he knew how to talk to different people to make them understand. He, like, knew people. And my computer teacher, she just-she taught me a lot. So, like-I don't know. She just, she always sees the good things in the darkness, you could say."

In many cases, students wish for more opportunities. The limited opportunities appear to limit the options for exploration of interest areas.

P2: "We go to the smaller school, so it's (computer classes are) kinda limited. I just wish I had more opportunities (for computer classes and learning), and I don't know how I can really find ways to grow."

P4: "No, we don't select our classes we just get our schedule for middle school and then we do it."

P6: "We don't get to pick. We have to have certain classes."

\section{Career Perceptions}

Our research revealed that how a girl is introduced to a field of study or how she perceives a career influences her desire to learn more about the field or to turn away from the field.

P1: "I feel like I could go into if I really wanted to, because I'm pretty sure there are a lot of opportunities in that."

P3: (interested in cyber because she knows more about it) "I think I like them more because I just know more about it after the camp."

P8: "Just seeing how good they could be and knowing that they had to try really hard to get there and that I can do the same."

Exposure to a variety of professionals and the opportunity to interact with role models can strongly influence career perceptions.

P7: "A person that I picture is someone that looks like Pam because I know her and that she works with computers a lot, so she comes to my mind."

\section{Community Groups}

Social groups, educational groups, and sports teams influence and motivate students in their selection of extracurricular activities.

P10: "I feel good because I feel like I'm on a team and I like being with a team and supporting them."

P9: "I'd rather work with other people to get like different opinions."

P5: "It (sports) is fun because I get to have fun with my friends and learn new things and it's another activity to be a part of."

Groups and community activities can also be frustrating. The exposure they provide may provide awareness they are mis-matched to the activity. Students may find that they do not have the attitude or aptitude for an activity.

P2: "Sometimes it's a little frustrating, because you know that you're screwing up and other people are screwing up, and you can't change what other people are doing."

P8: "Well, one time when I was about 7 or 8 I tried soccer for a while and I thought it was going to be really fun but I really didn't enjoy it that much."

\section{Individual}

Adolescent girls are making their own designs and forming their own opinions. Girls seek opportunities that they would like to explore and leave activities that they do not enjoy.

P2: "I just wanted to try out sports and kinda see what I liked."

P3: (who inspires you to try activities) "just myself. I just do a sport or anything that I would like to participate in." 


\section{Issues in Information Systems}

Volume 20, Issue 1, pp. 168-177, 2019

P5: "Because it's interesting to see what you're actually doing with like computers and all these little things like say coding, like one app could be doing this but it has many different steps in between - I like learning about that."

While other respondents had a preference for group interaction and opinions of others.

P9: "I'd rather work with other people to get like different opinions."

P10: "I feel good because I feel like I'm on a team and I like being with a team and supporting them."

\section{Family}

Family influence includes parents, siblings, and extended family. The interviews revealed that parents and siblings are highly influential in determining adolescent activities.

P1 shared that she joined wrestling (primarily a male sport) because her brother influenced her.

"I would always go to wrestling tournaments with my brothers, so that kind of inspired me to join wrestling, watching them all the time. I thought my brothers were really cool and they seemed to enjoy it."

P3: "My mom inspires me to do things. She always wants me to do the best that I can."

P4 also had an experience of being influenced to start a primarily male activity and discovering that she enjoyed it:

"When I was little my dad would always bring home ducks he shot and I started to like that and now I hunt all the time."

Sometimes the influence of a family member can cause a change of mind as in the case of P10 who went out for a sport because of family influence but discovered she did not like it.

P10: "All my siblings were in cross country and so I started it and discovered I didn't like it."

P2: "Yeah. Well, my mom found the camp, and I wasn't really interested, but then she contacted my friend and my friend was, so I went with her."

There is an opportunity to influence adolescent girls to engage in cybersecurity education and consider cybersecurity careers. The SCCIF Model identifies the Influencers and emphasizes the possibility of a circular process which the influence may transition through. It is important to recognize that influencers may have positive, negative or neutral effects. The data indicates there is possibility of cycling through positive, neutral, negative responses to Influencer actions.

\section{CONCLUSION}

This research answers the research question, "What are the adolescent girls' influencers as related to exploration of the cybersecurity field?" by providing a strong contribution with the addition of the SCCIF Model to enhance the CISSE model. We explored the influencers using qualitative research methodology to discover the types of factors influencing middle school girls from their perspective. The insight gained from the model which indicates that the top influencers are school, career perceptions, community groups, individual, and family. The influencer areas have positive, neutral, and negative responses that can influence a female adolescent's behavior. The contributions from this research can influence middle school cyber education, outreach efforts, and recruitment and retainment of girls in cyber. Social media outreach focused on STEM can also gain insight from this research on influencing adolescent girls.

Previously, the CISSE framework assisted in developing and enhancing the comprehensive program called CybHER $^{\mathrm{TM}}$. The CybHER ${ }^{\mathrm{TM}}$ program has impacted over 14,000 girls and contributed to a $300 \%$ increase over five years of women studying cyber sciences at a Midwest University in the United States. The CybHER ${ }^{\text {TM }}$ program is focused on empowering, motivating and educating middle school girls to pursue cybersecurity degrees (Rowland, Podhradsky, \& Plucker, 2018).

There is a severe shortage of personnel in the cybersecurity field that will take several decades to accommodate. Women are largely under-represented in cybersecurity degree programs and the profession. Recruiting and retaining woman has been a persistent problem at universities and within the industry. The Bureau of Labor Statistics states that "employment of computer and information technology occupations is projected to grow 12 percent from 2014 to 2024, 


\section{Issues in Information Systems}

Volume 20, Issue 1, pp. 168-177, 2019

faster than the average for all occupations." (Occupational Outlook Handbook, 2016). The recruitment and retention of students in cybersecurity is critical to achieve the workforce necessary to meet projected demand. Increasing the number of female students provides a great opportunity to expand workforce talent, diversity, and skills. The expanded SCCIF model builds on the CISSE model and provides more insight to broaden awareness and participation of the role influencers may play in the participation of girls in cybersecurity and related career paths.

The importance of identifying the influencers and providing the influencers with the preparation and materials to advise and educate at the middle school level is key, while increasing the confidence necessary to encourage development of environments conducive to further exploration of opportunities in cybersecurity field.

\section{Future study and limitations.}

Although the sampling technique and purposiveness allowed for the development of in-depth and rich information about middle school girls' perceptions, there are some limitations. Most interviewees were from one region in the Midwest and interviewee selection was assisted by principals, teachers and parents. For future research, expanding the interviewee pool to include broader representation would expand the research. In addition, comparing female students' responses to male students would indicate if the perceptions were unique to females, if there were crossover, or if any were uniquely different.

\section{REFERENCES}

(ISC)2. (2018). Cybersecurity Professionals Focus on Developing New Skills as Workforce Gap Widens. Retrieved from https://www.isc2.org/-/media/ISC2/Research/2018-ISC2-Cybersecurity-WorkforceStudy.ashx?la=en\&hash=4E09681D0FB51698D9BA6BF13EEABFA48BD17DB0

Anderman, L. H., \& Midgley, C. (1997). Motivation and middle school students. What current research says to the middle level practitioner, 41-48.

Berg, B. L. (2004). Methods for the social sciences: Pearson Education Inc, United States of America.

Biernacki, P., \& Waldorf, D. (1981). Snowball sampling: Problems and techniques of chain referral sampling. Sociological methods \& research, 10(2), 141-163.

Brown, R., Brown, J., Reardon, K., \& Merrill, C. (2011). Understanding STEM: current perceptions. Technology and Engineering Teacher, 70(6), 5.

Bybee, R. W. (2010). What is STEM education? In: American Association for the Advancement of Science.

Catherine Ashcraft, E. E., Michelle Friend. (2012). Girl's In IT: The Facts. Retrieved from https://www.ncwit.org/sites/default/files/resources/girlsinit_thefacts_fullreport2012.pdf

Charmaz, K. (2006). Constructing Grounded Theory: a Practical Guide Through Qualitative AnalysisSage Publications Ltd. In: London.

Cheryan, S., Drury, B. J., \& Vichayapai, M. (2013). Enduring influence of stereotypical computer science role models on women's academic aspirations. Psychology of Women Quarterly, 37(1), 72-79.

Cooper, J. (2006). The digital divide: The special case of gender. Journal of Computer Assisted Learning, 22(5), 320-334.

Corbin, J., \& Strauss, A. (1990). Basics of qualitative research: Grounded theory procedures and techniques. Basics of qualitative research: Grounded Theory procedures and techniques, 41.

Corbin, J., \& Strauss, A. (2014). Basics of qualitative research: Techniques and procedures for developing grounded theory: Sage publications.

Cracking the Gender Code in Computing - Accenture and Girls Who Code. (2016). Retrieved from https://www.accenture.com/us-en/cracking-the-gender-code 


\section{Issues in Information Systems}

Volume 20, Issue 1, pp. 168-177, 2019

Dasgupta, N., \& Stout, J. G. (2014). Girls and women in science, technology, engineering, and mathematics: STEMing the tide and broadening participation in STEM careers. Policy Insights from the Behavioral and Brain Sciences, 1(1), 21-29.

Draucker, C. B., Martsolf, D. S., Ross, R., \& Rusk, T. B. (2007). Theoretical sampling and category development in grounded theory. Qualitative health research, 17(8), 1137-1148.

Dutta, S., \& Mathur, R. (2012). Cybersecurity-An integral part of STEM. Paper presented at the IEEE 2nd Integrated STEM Education Conference.

Ellis, D. (2019). Security Trends: Data Breach Statistics from 2018 and Predictions for 2019. Retrieved from https://www.securitymetrics.com/blog/security-trends-data-breach-statistics-2018-and-predictions-2019

Flouri, E., \& Buchanan, A. (2002). The role of work-related skills and career role models in adolescent career maturity. The Career Development Quarterly, 51(1), 36-43.

Glaser, B. G., \& Strauss, A. L. (2009). The discovery of grounded theory: Strategies for qualitative research: Transaction publishers.

Grabisch, M., \& Rusinowska, A. (2010). A model of influence in a social network. Theory and Decision, 69(1), 6996. doi:http://dx.doi.org/10.1007/s11238-008-9109-z

Grossman, J. M., \& Porche, M. V. (2014). Perceived gender and racial/ethnic barriers to STEM success. Urban Education, 49(6), 698-727.

Harter, S. (1996). scholastic motivation, self-esteem. Social motivation: Understanding children's school adjustment, 11.

Iteea. (2019). International Technology and Engineering Educators Association. Retrieved from https://www.iteea.org/

Jethwani, M. M., Memon, N., Seo, W., \& Richer, A. (2017). "I Can Actually Be a Super Sleuth" Promising Practices for Engaging Adolescent Girls in Cybersecurity Education. Journal of Educational Computing Research, 55(1), 3-25.

Kleck, R. E., \& Strenta, A. (1980). Perceptions of the impact of negatively valued physical characteristics on social interaction. Journal of personality and social psychology, 39(5), 861.

LeClair, J., \& Pheils, D. (2016). Women in Cybersecurity: BookBaby.

Margolis, J., \& Fisher, A. (2003). Unlocking the clubhouse: Women in computing: MIT press.

Mendoza-Denton, R., Downey, G., Purdie, V. J., Davis, A., \& Pietrzak, J. (2002). Sensitivity to status-based rejection: implications for African American students' college experience. Journal of personality and social psychology, 83(4), 896.

Midgley, C., Feldlaufer, H., \& Eccles, J. S. (1989). Change in teacher efficacy and student self-and task-related beliefs in mathematics during the transition to junior high school. Journal of educational Psychology, 81(2), 247.

Moorman, P., \& Johnson, E. (2003). Still a stranger here: Attitudes among secondary school students towards computer science. Paper presented at the ACM SIGCSE Bulletin.

Morgan, S. (2018). Women Represent 20 Percent Of The Global Cybersecurity Workforce In 2019.

Neuman, L. W. (2002). Social research methods: Qualitative and quantitative approaches.

Occupational Outlook Handbook. (2016). Washington, DC: U.S. Bureau of Labor Statistics Retrieved from http://www.bls.gov/ooh/computer-and-information-technology/home.htm.

Op-Ed: To Close Gap in STEM Pipeline, Engage Families. (2018).

Pajares, F., \& Schunk, D. (2001). The development of academic self-efficacy. Development of achievement motivation. United States, 7. 
Petroff, A. (2017). The exact age when girls lose interest in science and math - Feb. 28, 2017.

Rowland, P. (2018). The CybHER program supported by CISSE framework to engage and anchor middle-school girls in cybersecurity. Dissertation (D. Sc.)--Dakota State University, 2018.

Doctor of Science in Information Systems.,

Rowland, P., \& Noteboom, C. B. (2019). Adolescent Girls' Influencers in Cybersecurity Education and Activities. MWAIS 2019 Proceedings.

Rowland, P., Podhradsky, A., \& Plucker, S. (2018). CybHER: A Method for Empowering, Motivating, Educating and Anchoring Girls to a Cybersecurity Career Path. Paper presented at the Proceedings of the 51st Hawaii International Conference on System Sciences.

Rozek, C. S., Hyde, J. S., Svoboda, R. C., Hulleman, C. S., \& Harackiewicz, J. M. (2015). Gender differences in the effects of a utility-value intervention to help parents motivate adolescents in mathematics and science. Journal of educational Psychology, 107(1), 195.

Securing Our Future: Closing the Cybersecurity Talent Gap. (2016). Retrieved from $\mathrm{http}: / / \mathrm{www}$. raytheoncyber.com/rtnwcm/groups/cyber/documents/content/rtn_278208.pdf

Shapiro, J. R., \& Williams, A. M. (2012). The role of stereotype threats in undermining girls' and women's performance and interest in STEM fields. Sex Roles, 66(3-4), 175-183.

Shih, M., Pittinsky, T. L., \& Ambady, N. (1999). Stereotype susceptibility: Identity salience and shifts in quantitative performance. Psychological science, 10(1), 80-83.

Shumba, R., Ferguson-Boucher, K., Sweedyk, E., Taylor, C., Franklin, G., Turner, C., . . Hall, L. (2013). Cybersecurity, women and minorities: findings and recommendations from a preliminary investigation. Paper presented at the Proceedings of the ITiCSE working group reports conference on Innovation and technology in computer science education-working group reports.

Statista. (2019). U.S. data breaches and exposed records 2018 | Statistic.

Steele, J. R., \& Ambady, N. (2006). "Math is Hard!” The effect of gender priming on women's attitudes. Journal of Experimental Social Psychology, 42(4), 428-436.

Technology. (2019). Definition of technology | Dictionary.com.

Young, D. M., Rudman, L. A., Buettner, H. M., \& McLean, M. C. (2013). The influence of female role models on women's implicit science cognitions. Psychology of Women Quarterly, 37(3), 283-292. 